\title{
SCIENCE AND WISDOM
}

\author{
Gabriel Marcel
}

\section{Translated by Maurice Cranston}

\section{Editor's Note}

Gabriel Marcel delivered this lecture at the College of St. Catherine (CSC), St. Paul, MN on March 12, 1965. An audio tape recording was made of that presentation. Marcel also gave the lecture at St. Olaf College, Northfield, MN in November 1965. According to the program announcement for the CSC lecture, the title was "Wisdom in the Technological Age", although, on the audio tape, Marcel specifies the lecture title as "Science and Wisdom", the title which appears in his printed lecture notes.

It is also interesting to note that on the CSC program announcement, Marcel delivered another talk on March 11 entitled "The Myth of God in Contemporary Thought." However the text of that talk,edited by Ulrich Scott and published as a pamphlet for CSC by the Gilbert Publishing Co. of Minneapolis, is entitled "Man Before the Death of God".

During the following week, specifically March 18-19, 1965, Marcel received an honorary degree from LeMoyne College, Syracuse, NY. At that time, he delivered a talk, "Man Before the Alleged Death of God". Judging from K.R. Hanley's careful summary of that lecture, published in The Heights: The LeMoyne College Magazine, 1965, and a copy of Marcel's lecture notes, the text was substantially the same as the CSC "Man Before the Death of God" lecture published in the pamphlet.

Maurice Cranston, who passed away in November 1993, was a professor at the London School of Economics and Political Science. Besides authoring many books and articles on a multitude of topics, Cranston did much translation from French into English, including a Penguin edition of Jean-Jacques Rousseau's Social Contract, 1968. A recent complete bibliography of Cranston's works complied by Calliope Farsides is in Lives, Liberties, and the Public Good: New Essays in Political Theory for Maurice Cranston, edited by George Fearer and Frederick Rosen, New York: St. Martin's Press, 1987, pp. 259-266.

An earlier version of "Science and Wisdom" was delivered in Freiburg in Breisgrau in 1963. That was published in German by Verlag Knecht, 1964, in a collection of Marcel's lectures entitled Auf der Suche nach Wahcheit und Gerechtigkeit. An English translation (the translator is not identified) of that collection was published by the Newmann Press in 1967 with the title 


\section{Searchings.}

This publication of "Science and Wisdom" is the very lecture notes Marcel used for the talk at CSC and St. Olaf and is significantly different from the earlier Searchings version. Marcel's handwritten corrections of Maurice Cranston's translation have been integrated into the following text. Also, Cranston's British spellings of certain words, e.g., "centre", "specialisation", etc., have been retained as Marcel did not correct any of them. Finally, for the sake of grammatical clarity and/or amplifying philosophical content, Marcel's important oral additions to the printed lecture notes as recorded on the CSC tape have been included within brackets. Where Marcel in his oral presentation substituted a word or phrase for what appeared in the printed text, the substitution is noted as [substituted: -].

There are many people who deserve to be acknowledged for their assistance with this publication of "Science and Wisdom." Sr. Majorie Smith, CSJ, of the CSC library archives was most forthcoming with her time and extremely helpful in providing the materials pertaining to Marcel's visit in March 1965. Professor Howard Hong and Cynthia Lund of St. Olaf College also communicated valuable background information on Maurice Cranston and Marcel's presentation of "Science and Wisdom" at St. Olaf. K.R. Hanley was very generous in supplying a copy of her essay in The Heights and a recollection of Marcel's time at LeMoyne. Finally, Jean-Marie Marcel, Gabriel's son and executor of the Présence de Gabriel Marcel in Paris, has our sincerest gratitude for graciously authorizing this publication of "Science and Wisdom."

I think I shall be understood better if I begin by defining the terms of the problem I am going to discuss this evening, a subject to which I have given the very general title, Science and Wisdom.

In the world of today - a world so obviously controlled by science, or, more precisely, by the infinitely various and everexpanding techniques that make up science - what meaning can one still give to the word "wisdom"? What we shall be concerned with is that change in people's attitude to life which is the result of the hegemony of science and its techniques. This is another way of saying that our problem is of an existential or phenomenological kind. It is a matter, above all, of knowing whether wisdom itself is not in danger of degenerating into a collection of technical procedures and in doing so of losing that supreme value ascribed to it by the moralists of the past.

If, however, I have preferred not to be more specific in the title, 
not to call my subject, for example, "Science and Wisdom in the World of Today", it is because it has seemed to me impossible not to refer, at any rate up to a certain point, to the history of thought. Assuredly, there could be no question, within the limits of a single lecture, of covering the whole history of the problem. In principle, it is clear that one ought to go right back to the history of ancient thought, beyond the Epicureans and the Stoics, to Plato. But I shall limit myself to seeking historical bearings in the thought of the seventeenth century, and particularly in that of Descartes, and then to showing how the problem developed in the eighteenth century and after, with the coming of Romanticism, on the one hand, and the success of evolutionary ideas on the other.

In the preface to the French edition of Descartes' Principles of Philosophy, there are important passages which characterise very well some aspects, at any rate, of Cartesian thought: I quote: "The word 'philosophy' means the study of wisdom; and by 'wisdom' one means not merely prudence in the affairs of the world, but a perfect knowledge of all those things that a man should know, as much for the conduct of his life as for the preservation of his health and the invention of all arts." Descartes adds that this knowledge must be deduced from first causes; and he indicates the means by which one acquires that "wisdom we customarily have" (whether a notion which is clear and distinct in itself, or the result of some experience, or of conversation with other men, or of reading books written by authors qualified to give us good instruction). It is in the same preface that we find the famous remark: "The whole of philosophy is like a tree, of which the roots are metaphysics, the trunk physics, and the branches the other sciences, which may be reduced to three main ones, namely, medicine, mechanics and ethics - that is to say, the highest and most perfect ethics, which, presupposing an entire knowledge of the other sciences, is the ultimate degree of wisdom". (Pléiade Edition, p. 428).

What is remarkable in these passages is the range that Descartes gives to the word "wisdom": one is almost tempted to say that wisdom is here co-extensive with knowledge. It seems to be taken for granted that whoever progresses in knowledge raises himself at the same time in what we might call the moral domain. Nevertheless it would be useful to introduce a limitation at this point. 
For Descartes is really far from identifying the intellect with the will. The will is, in itself, infinite; human understanding is definitely not; and it is this disparity which sets up the possibility of error and in particular of moral error.

My friend and colleague, Henri Gouhier, one of the leading Descartes scholars, has drawn my attention to a letter written - not to Mersenne as is stated in the Pléiade edition, but to Father Mesland, and dated February 9, 1645. Descartes speaks here of the freedom of indetermination. "I have never denied", he says, "that this positive faculty exists in the will, far from it; I believe that we meet it, [notably] in those those kinds of actions, where the will is not carried by a strong pressure of any motive towards one direction rather than another; but that it is also revealed in all other kinds of actions; so that the will is only ever determined by that faculty that brings it into use, so much so that, at the very moment when a compelling reason carries us towards one thing, though, morally speaking, it might be difficult for us to do the contrary, yet, speaking absolutely, we could do the contrary, for it is always open to us to stop ourselves from doing what is clearly known to be good, or to stop ourselves assenting to a manifest truth, so long as we believe it is a good thing to bear witness by such means to the freedom of the will". These were Descartes' words.

In the case of Spinoza, on the other hand, we are confronted by a radical intellectualism: the will and the intellect are one and the same thing. Here the idea of the Sage assumes at once a simplicity and a perfect coherence. The Sage is the man who has liberated himself from the snares of the imagination and from the yoke of the passions. But this liberation is itself effected by the exercise of the intellect. "In so far as the mind understands all things as necessary, in that same measure it enlarges its power over the passions and frees itself from their yoke". (Ethics, Book V, prop. 6). But it is very obvious that the Spinozistic thought is not to be placed in what we should nowadays call a psychological perspective. "He who understands himself clearly and distinctly, and also his own passions, loves God, and he does so the more fully as that understanding is the greater". (prop. 15).

But we know well enough that, for Spinoza, that third kind of knowledge which belongs to the Sage, in other words, to the fully 
liberated mind, is a knowledge which must be distinguished from the second kind of knowledge, which never goes beyond the level of abstractions and generalities. It would be rash to say that for Spinoza the Sage and the Scientist are strictly identical. The word "scientist" is in danger of leading us astray here, since we may doubt that Spinoza used the word in the sense that we give it today. On the other hand, Spinoza did without any doubt recognize that simple beings - by which I mean those lacking in scientific knowledge in the strict sense of the term, that such beings might, nevertheless, acquire, if not the third kind of knowledge, at least its equivalent and the true love of God.

All this, of course, raises difficult problems of interpretation. We know well enough how many controversies have risen over the interpretation of Spinoza. Even so, provided it is understood that one is simplifying somewhat the data of very complex realities, we may rightly regard Spinoza as the leader of a procession of Rationalist philosophers, who afterwards, and still today - even though their number is undoubtedly diminishing - assert without hesitation that progress in knowledge [that is to say, in science] necessarily entails progress in Wisdom. This confidence is especially manifest in the Aufklärung, the Enlightenment, although even again certain qualifications must be introduced in the case of the really first rate thinkers. At all events, we can say that in this tradition of thinking, the crucial notion is that of association [and sometimes of identity] between the intellect and the will.

But in the Eighteenth Century, probably in the wake of Fénélon, and certainly among the English, and, needless to say, in the case of Rousseau, there emerged an altogether new conception of the moral sense and affectivity, one which was more and more opposed to Cartesian intellectualism. It seems moreover that the notion of wisdom tended to suffer at the same time a certain devaluation. In the case of Goethe, the very fact of his Spinozistic sympathies preserved for wisdom its preponderance, though he sees it as the mark of something rather strictly aristocratic; on the other hand, with the Romantics [especially the German Romantics, but also perhaps the English, like Coleridge] wisdom, it seems to me, underwent a sort of dissociation: we can distinguish on the one hand, rules of prudence, regarded with a certain disdain, governing the 
conduct of life, rules which are dependent on the simple understanding, on the igenium; on the other hand, the Romantics recognized, in order to exalt, a wisdom above wisdom, derived from intuition, or, in any case, from faculties not reducible to the understanding or discursive knowledge. A certain convergence might also be discerned between these romantic views and the purely Christian conception of a sacred wisdom which is madness in the eyes of secular wisdom [substitute: understanding].

In every way, wisdom, in so far as it does not reduce itself to mere sagacious counsel, tends to appear as something wholly irreducible to knowledge - if not to knowledge in general, at any rate to the knowledge which is expressed in empirical science. In fact it seems that the more the sciences tend towards specialization, the harder it becomes to find a link between them and that kind of intuitive knowledge, a knowledge which is perhaps in some ways close to Art, the art of living, which still deserves the venerable name of wisdom. Things emerge rather as if each particular science, taken alone, tended to barricade itself against the temptation felt by every layman to encroach on human existence - and here I take the word "existence" in its contemporary meaning, whether it entails explicit normative evaluations or not.

[A good example might be drawn here from medicine. Still at the end of the nineteenth century and in the first years of this century, a doctor, a medical man, was usually considered as a man whose advice even outside the body state (physical condition) could be valuable. One felt that the doctor had a certain survey of life which enabled him to be wise. But so far as medicine has split into specializations, this is no more the case. One would not usualiy think that a cardiologist, for instance, a specialist of the heart or another organ, kidney's if you like, would be entitled to give wise advice as to the conduct of life. This of course may happen, but what I mean is that connection between medical knowledge and wisdom which still existed 50 years ago, now exists no longer. And this, I think, is an important fact.]

To look at another side of the picture, the success of evolutionistic theories tended to accredit what was otherwise called wisdom to a biological concept, namely, the idea of the adaptation of 
man - man considered essentially as a living, rather than a thinking being, in the milieu in which he enacts his role. Now this is the schematized expression of much more complex data. For the evolutionist philosophers, of course, tried to incorporate in their theories, with varying degrees of success, certain elements taken from earlier doctrines.

On the other hand, it goes without saying that some thinkers among them - say, for example, Nietzsche, from one side, and Bergson, from the other - expounded a philosophy of life infinitely [substitute: incomparably] richer than that of their predecessors. From the moment that life is conceived as creation, it becomes a question for Man to participate actively in that very creation, if only because the milieu he lives in is no longer considered as a fixed datum, but as something itself susceptible of being renewed and transformed. But this does not happen without bringing a radical change in the idea of wisdom itself. In the case of Nietzsche, we must of course pay great regard to the specific period of his thinking, which underwent such marked variations: we must, above all, distinguish two phases. First there is Nietzsche's criticism of attitudes or styles of evaluation, which continues - and at the same time enriches with new and profoundly original elements - the tradition of the French moralists from La Rochefoucauld to Chamfort. Secondly, and above all from Zarathustra onwards, there is something like the submersion of the critical element by a prophetic vision centered on the eternal cycle and the coming of the superman. I admit I am not sure that, in the process, Nietzsche's thought does not venture into regions which go far beyond what has been traditionally understood by the name of wisdom.

With Bergson, assuredly, things developed differently. But what is equally true in his case, is what being inspired, after a certain moment, by a religious reality that is nowhere apparent in his earlier writings, his thought seems to be on the point of greatly transcending that of the traditional moralists. [Here one ought to go into details especially about his distinction between closed and open morality.]

After these summary - these almost scandalously summary historical observations, it is time for me to come to the problem I spoke of at the outset. As I said, it is from an essentially phenomenological 
point of view that I intend to approach my subject.

In the first place, it seems to me that we need to listen carefully and detect the sound, the tone, that the word "wisdom" has for the majority of our contemporaries, and, naturally, I am thinking especially of the young. Briefly, we have to treat it like the sound of a musical instrument of which the quality, the timbre, is in question. One must frankly admit, I believe, that very name "wisdom" arouses, first of all, suspicion. And why? Because it seems to imply a priority being given to experience and even, in a way, to age. It is a word that savours of the old. And this sort of priority is quite rightly challenged, indeed denied. First because the old are, as a whole, held responsible for the tragic, perhaps desperate, situation in which the world finds itself today. [And, for the wars which we have known.]

Perhaps those who feel like this might express themselves in these words: "If what you call wisdom", they might say, "has played a role in the march of events, one can only say, in that case, it has been no better than the worst folly. Alternatively, if you claim that the world has developed as it has, in spite of the counsels of wisdom, one can only say that such wisdom has been ineffectual and non-existent. What is more, it has allowed a certain number of privileged persons to give themselves a feeling of moral comfort which seems to us today, very suspect."

Nor is this all. It will probably be noticed that wisdom, in all the forms that we know, seems [almost] invariably to imply a sort of acquiescence in the existing order of the world, or the social system; to imply, at any rate, a resignation: and, in this sense, wisdom runs the risk of being the accomplice of the worst conservatism.

These remarks all point to the same conclusion: one is led to say that wisdom is in danger of having nothing but a fallen and discredited existence [in the present world].

But can one not reply to such objections that they rest on a conception of wisdom that is far too narrow: and that the problem is precisely one of getting beyond these limitations, and finding the necessary conditions for doing so? But no doubt the rejoinder will be that it is both too easy and too dangerous to give the same name to 
mental attitudes that are very different, if not actually opposed to one another.

However, before we venture any farther in that direction, it will be useful to confront, more directly than I have so far done, the central question of the relation between science and wisdom.

Now, the use of the word "science" requires special precautions just as the word "wisdom" does.

If there is a region when Blondel's distinction between 'thinking thought' and 'thought thought' has a bearing, it is certainly that of science. One might say, I believe, that the function of the scientist as a scientist is to keep constantly to the level of 'thinking thought', while the scientific popularizer moves only on the level of 'thought thought' [that is to say, of thought already digested], or of empirical findings that he tends too often to raise to an absolute status by taking them out of the context to which they belong. A highly qualified young scientist with whom I was talking a few years ago, suggested to me that the layman is far from suspecting the part that approximation has played, even in the discovery of natural laws that are no longer questioned. It's commonly assumed, he said, that a scientific experiment can be reproduced as often as you like. In fact, we notice very often that this reproduction leaves much to be desired, as if, so to speak, the experiment contained a sort of dross, for it could only rarely be freed. Now this remark bears witness to a kind of perception that we never find among people who treat the results of empirical science as absolute.

If $I$ insist here, it is to recall that the real scientist is always on his guard against the scientific popularizer [substitute: vulgarization], and, against the temptation to define human conduct, for example, in terms of a theory of evolution passing off as a definitive discovery of truth. In this connection, I notice that one has no difficulty in finding today in France, or Germany, and no doubt elsewhere, scholars who bring out the limitations of existing theories of evolution, and what is speculative or hazardous in many statements of them: here I might mention, for example, the remarkable biologist Louis Bounoure, professor at the University of Strasbourg. 
But what has all this to do, you might ask, with our subject? Well, that the scientist, as a scientist, as a man engaged in research, gives good proof of wisdom in regard to those hasty and unreflective conclusions that men outside draw from his work. Let us take care to define the nature of this wisdom. It is essentially a cautiousness which would never express itself in the name of an objective certitude, like a certain kind of old-fashioned theology or dogmatic Marxism -- but which expresses itself rather in the name of those exigencies to which scientific research must itself submit if it is to be authentic research.

It would be obviously altogether absurd to accuse such wisdom or prudence, of being likely to dim a certain flame. This kind of condemnation, which stems from a sort of romanticism of knowledge, is indefensible, and could not stand up to any mature reflection.

It seems from what we have so far considered that science, regarded as 'thinking thought' carries in itself something which is really of the order of wisdom. But, important as it may be, that conclusion does not appear to have carried us much further. It is of no great interest, you will say, that the scientist, as a scientist, is distinguishable from what might be called the counterfeiters of science.

What, after all, does interest us, is Man. Should one say, Man in general? Now, this is a way of speaking that I have always objected to [and even rejected]. Let us say rather that Man is each one of us, seen existentially, that is to say, seen in the path that is given him to follow from birth to death. Yet it is obvious that this image of a path - if it corresponds in a way to the structure of the Being-Man, is, on the other hand, inadequate; for simply by reason of the fact that the path can be severed at any instant by death, the traveller that I am may see in death less a final term than a pressure, a constant imminence. Now, the word "may" is very significant here, for Man is not compelled to acknowledge this manifest pressure - and the problem then presents itself to him as one of knowing whether he is wise or not to actualize that possibility. This question does seem to call attention very precisely to what has always been known as wisdom, and one cannot see how it can be evaded - or rather to evade it is already in a way to resolve it. Can science, one might ask, be of any help to us here? Well, in any case, [this science] could only be psychology. But has psychology, taken as a science, in itself what is needed to answer a 
question, or even to understand its whole bearing? Of course, we all know the theory much favoured by the Americans according to which the very fact of thinking about death, except to take precautions to delay it, is considered morbid. The notion which comes in at this point - and it is closely tied to what I have already discussed - is that of "adjustment". Incidentally, it's interesting to notice here the surprising degradation in the Americanized world of the spinozistic idea that the sage does not think about death. But in reality what has happened is that 'the sage' has been replaced by 'the healthy man', the adapted or adjusted man who tries to get the most out of life.

It's a matter, on the one hand, of getting the normal satisfactions of life (as much in the realm of comfort and sport as of sexual relationships); but it is also a matter of assuming easily one's place in society; and, from this point of view, there is room, of course, for affection and generosity. The adjective 'decent', more current no doubt in England than the United States, is probably the one that best fits this conception - about which one can say that it tends to put what has always been regarded as wisdom at its lowest limit. Why lowest, you may ask? Well, because it seems to exclude everything of the nature of creation and, moreover, what is perhaps more serious, of interrogation - of that personal and anxious interrogation, without which many of us Europeans would feel that a man is not, strictly speaking, a man. Those who hold to that minimal conception of wisdom will go to a psychoanalyst when they notice in themselves difficulties of adjustment, just as one goes to a specialist in the digestive organs if one suffers from indigestion or constipation. It is highly significant that such an analogy must be invoked in this connection. The important thing is the idea, implicit or not, that what used to be called the spiritual life must now be regarded as a simple functioning that ought to follow certain rules, like the lungs, the heart and the liver.

These remarks have the utmost importance for our subject. But it is a matter of knowing exactly whether Science itself is responsible for this devaluation, or whether it is a philosophy that speaks in the name of Science if without authority. Certainly AngloSaxon positivism claims that there is an unbroken continuity between science and the kind of philosophy that resists metaphysics, resists all Welt- or Lebensanschauung. Our previous remarks were orientated 
rather differently, but this will become clearer in what follows. If I started out with the question of death, and the connection between death and the subject itself, that is because nothing else, perhaps, clarifies so well the opposition we are seeking to determine. All this might be developed in a variety of ways. A few years before the last war André Malraux told me that once, when he was in Moscow, where he was struck by the scientific optimism of his hosts, he pointed to a newspaper report of some tram or railway accident, and observed that for all the social progress that might be achieved, the tragedy of death would always exist - (Perhaps this was a kind of obscure premonition! Malraux's second wife was to die during the second war in an accident of this kind [and two sons of his died in a car accident]). However, they replied to him in Moscow that in the future the trams and the railways would work so perfectly that such accidents would be avoided. The astonishing blockheadedness of such an answer surpasses any comment. Nevertheless it is very significant. Death is here regarded as a normal cessation of a functioning which happens normally when the apparatus has completed its term. It is no more tragic for a man than for the apparatus or machine in question. [And, they would add,] it is only a morbid mind that would raise itself against what is, once more, quite normal. Here again, we can see very clearly the common denominator between Soviet thinking and [a certain] American thinking: both tend towards a purely technocratic outlook.

One might go on from this to point out a close analogy with the idea of love, which also runs the risk of degradation in the same perspective. Here, as before, the danger is of what might be called an indefinite deflation of human reality. We shall be able to distinguish in what is commonly called love, only the instinct of procreation on the one side, and on the other certain satisfactions that must be regulated in such a manner as to spare the individual any disequilibrium liable to disturb the exercise of his social duties.

Still, the question remains. Are we here in the presence of something which follows logically from the nature of Science? One ought to be more precise at this point, and bring in the idea of a scientific anthropology. But it is obvious that a fundamental question is implied by all this: and that is the question of value - judgement itself. 
I was very struck to notice in the United States that the philosophers of the Logical Positivist school are inclined for the most part to assert that all value judgements are in reality no more than expressions of personal preference; which comes, in effect, to saying that such judgements have a deceptive, or fraudulent, character. To adopt a position of this kind is, in fact, to reduce wisdom to a personal rule of living that cannot be universalized. One comes out in the end with a sort of moral dietectics. But again one might observe that even a diet implies the idea of health: and it is just that idea which is put in question here.

However, if we remember what has been said earlier, we shall not fail to ask ourselves whether a science that is more conscious of -1 shall not say merely its limits, but the very immanent conditions of its being - whether such a science would not have [to display] a humility that is of the order of genuine wisdom. Let us try and make this more concrete.

Why, first of all, do I put such stress on humility? Because scientific progress, if it is seen as a whole and with all its technical developments, does seem to offer a permanent inducement to the most excessive pride. In this connexion, it is difficult to attach too much importance to the exploits of the astronauts and to those scientists whose calculations have made their exploits possible. Never before has the eritis sicut Dii of the Scriptures found so striking an application. But can we rebut the idea, formulated with such exceedingly great force by the ancients, that pride [substitute: hubris] makes men mad?

We can at any rate confront an objection. Suppose it remains true, that in the case of one individual, pride leads to a disturbance of the mind, does this necessarily remain true of humanity taken as a whole? We might put the question differently: if we see clearly the individual's responsibility (in regard to society, or even in regard to humanity as a whole), does this word have a meaning for humanity generally? Naturally I put the question outside the framework of theology, since the responsibility of Man before God retains all its meaning for those who argue from Christian premisses. But here we have to set aside this example, since the idea of wisdom [as we have considered it] seems to be, in principle, [rightly or not] a secular one. 
I have spoken of humanity as a whole. But to reflect is to realise that this global way of talking does not correspond to any reality. First, it is by means of a crude fiction that we can think of humanity as a totality. There is also something contradictory in it - for me, who forms a part of humanity, to put it in front of me as total whole. It would be more useful to come down to brass tacks. What do we really envisage today? Are we to speak of a body or college of international scientists being invested by the mass of living men with unlimited power? If this were so, it would be the scientists who would have reason to proud. But the idea of such a mandate is entirely fictitious. Another thing and it is something much more serious - we could not possibly dissociate the scientists from the governments which give them the necessary means to those ends which scientists themselves are not always ready to appreciate, by reason of that confusion which always arises between genuine designs and the principles invoked. So what conclusion does this lead to for our present subject? It is that in incriminating science here, we run a grave risk of placing the responsibility where it does not lie.

And yet, a deeply disturbing question arises at this point notably one concerning the state of mind of the scientist who sees that his discoveries are used for ends that he himself condemns and that he considers harmful for humanity. Can we be satisfied with the convenient solution which consists in distinguishing the scientist from the man? This comes down to saying that the scientist, as a scientist, has no concern with consequences; while the man himself feels obliged to take them into consideration. It seems to me that Einstein, for example, would have refused to lend himself to this kind of dissociation. When he protested, with such heart-felt vehemence, against the military use of atomic energy, he certainly had no feeling of having set aside in any way his role of scientist.

It seems to me that what emerges here is that we are all concerned with the idea of truth. No doubt, one must find a middle term between utilitarianism, or the pragmatism that subordinates what we call truth to certain practical ends, on the one hand, and, on the other, a kind of idolatry of truth that makes it a sort of Moloch to which everything must be sacrificed, even, if necessary, the human race. Even so, I believe that we have gathered something as we have 
progressed - I do not say the elements of a solution, but some indications, more or less, that help us to see in which direction we should set ourselves. Remember what was said about the considered mistrust of the true scientist towards the simplifications that satisfy the popularizer. What is at the heart of such thinking is a research for which the scientist has always to clarify more precisely the immanent conditions, so that the problem of method remains perpetually present. But research as such does not allow one to hypostasize: a negative, but crucial advantage. It does not allow one to separate research from the man who conducts the research, and so revert to the anthropology I have spoken of. Today to conduct scientific research is undoubtedly and essentially to work in company with others, and this requires at least a minimum of good-will. Research thus implies a disposition that moves in the spirit of peace, and is on the threshold of love.

Assuredly, we have all to avoid closing our eyes to certain disturbing realities: I think, for example, of the practical experiments conducted by a great many Nazi doctors on living prisoners. And it is unfortunately not impossible to imagine other doctors, in another country, yielding to the temptation to make use of human merchandise that other tyrants may place at their disposal. What is, alas, clear, is that to be a researcher, far from excluding sinister possibilities, helps to favor them. We could, in truth, reassure ourselves by noting that in the world today at least, there exists a [certain] consensus of opinion among scientists which forbids such observations. But, I repeat, this is in the world today. We do not know what is going to happen tomorrow. The growth of population may lead to a debasement of human existence so radical, and human life may be so depreciated, [so cheapened], that it will come to be thought superfluous to surround it with the precautions and the respect that it enjoys today and indeed such respect and such precautions may even appear contrary to the common sense of the future.

We have stumbled here on another problem which illustrates very well that embarrassment which is felt by the man of today who questions himself about the relations between science and wisdom: and this is simply the problem of over-population. In the face of ever increasing difficulties which are likely to emerge with an unlimited 
increase in the population of the globe, we may ask whether the scientist, as a scientist, has the competence to give to men advice that looks like wisdom; and in a case like this, does not the distinction between science and wisdom run the risk of being obliterated: At first sight, that looks unlikely. Clearly, Science must concern itself with the problem, and seek to solve it in the sphere which is its own, that is to say, of striving to find the means of nourishing this excessive population. But does Science not trespass beyond its right in venturing into the sphere of private life? Would not the scientist be arrogating a function which is not his own? Here, once again, we must be more specific. In this world of ours - and here I speak of us Westerners - it will surely not be allowed that the right, which belongs to a couple to decide the question of procreation, should be restricted from outside in the light of conclusions reached through research controlled by [perhaps] an international organisation? And what about the question of keeping alive old people whose social usefulness has fallen to zero? It is perfectly conceivable, and, to my mind, very plausible, that if the process of secularisation which is already going on so fast in the world, goes on even faster, then the barriers which still hold today may be overthrown. It is necessary to add that what I am talking about here is technocratic development as such, [either] in an Americanized world or a Soviet world.

But the question that must exercise our minds remains always the same: namely, the question of whether Science itself is to be put in the dock. The answer must, I feel, be full of nuances. We come back to what I have said already. Certainly, Science, with that power not only over Nature but also over Man himself, which it has given to humanity, has clearly helped to lead men into temptation; and one can hardly believe that it has helped to develop in people's minds the means and the inner resources needed to resist that temptation; for there is no hiding the fact that what I have said about the humility of the true scientist does not apply to what one might call, as a mass, the science-mongers, that is to say, the innumerable multitude of those who, at various levels, benefit from the work of scientists, and transmit it to others. In any case, on this plane nothing, absolutely nothing, is guaranteed. I have often said in the past that scientific techniques are likely to be dangerous from the moment that they are no longer put at the service of ends higher than the technical - and science, I fear, without denying those ends, ignores them. More precisely, 
techniques are in danger of being used - as we can see more and more in Western countries on both sides of the Atlantic - in danger of being used for ends which occupy a decidedly inferior place in the hierarchy of values established by the sages of the past. Obviously, we are faced here with a tangle of problems. For it can always be claimed that the traditional hierarchy is meaningless, or is only possible in an aristocratic system incompatible with the world we see before us today, which is the world of the masses. However, that rejoinder is itself open to criticism; for if we take it literally we see that it entails a sort of acquiesence in the degradation of the human race. Everything depends on what you mean by "aristocratic". Can we honestly be satisfied with a levelling that is just a levelling-down? Can we dispute the creation, from among the masses themselves, of new aristocracies - though admittedly not those based on blood or wealth?

However that may be, it seems to me impossible to uphold for an instant the notion that science - I deplore having to use this excessively general and abstract word - that science could in any way furnish a justification for that sort of radical egalitarianism that Nietzsche and Scheler demonstrated to be rooted, primarily, in resentment.

We have come perilously far from our central theme, and the subject of this lecture. So perhaps I ought to wind up by saying more explicitly what has emerged in the course of this rambling pilgrimage.

In the first place, I argued that we ought to maintain a radical distinction between wisdom and that kind of generalized hygiene to which technically-minded people try to reduce it. For my own part, I think it is a matter of re-discovering the common root of propriety and justice. To use a musical idiom, as I often do, I should say that justice is, above all, a steady reference to a certain keynote which we find as much in the case of Marcus Aurelius as in that of Socrates, or Goethe, or Spinoza. This keynote cannot perhaps be defined without losing its value: I would say it is an essence, though not an essence - in the sense of an objectifiable content, but rather a crystalisation of the Light, about which I have said elsewhere that it is at the same time, Joy in being Light. [And, of course, this is purely Johannic.] But this takes us towards a centre around which we have ceased to gravitate for the pure joy of the scientist, whose work develops well, is nothing 
but an expression of that same joy: perhaps indeed we should regard the gaudium cognoscendi as an anticipation of that Laetitia Contemplandi which is the supreme end of our life's journey on earth.

I venture to say that there is not, and cannot be, 'atonal' wisdom. In life atonality is confusion and frenzy, while wisdom, in the last analysis, is perhaps a joyous effort to clarify and master life, just as science, on its side, is a victory over the fantasies of ignorance and fear.

It is thus, perhaps, that we reach, in the terms of our inquiry, a sort of convergence.

There is wisdom wherever a man seeks, I do not say to organize, but to order his life around a centre which makes the mere concern to sustain one's existence and interests appear peripheral and subordinate.

But Science itself is reduced to a scattered heap of knowledge if it is not constituted around a centre. One need only add here that this centre remains much more veiled than it does at the level of personal life, and this is perhaps the cause of the difficulties we meet. I will say in passing that to speak of truth in a certain voice is probably to betray the very spirit of science, which is research. Naturally I must add that one does not engage in research for the pleasure of research. Perhaps one ought to say that one tries to make the universe as much as possible inward: but beware lest assimilating the universe inwardly should turn out to mean possessing it, to do with it what you please. For in this there is always a risk of an aberration; and thus of the essential and pure intention of the scientist being dangerously corrupted. To assimilate inwardly $-\mathrm{I}$ believe that this must be understood in a very different sense; in the sense, for example, that we seek to assimilate inwardly a poem or a piece of music. This does not mean being able to play the music or write the poem. It is rather a matter of achieving a certain consonance with the world; not by means that belong to the imagination, but by a method that has, on the contrary, its own rigor.

Now, how come it is scientists appear rather seldom to be themselves aware of this end? Can it be that their minds are so 
concentrated on means which they never cease to perfect and sharpen that they lose all possibility of apprehending an end which cannot be expressed in the language of those means? Part of the duty of the philosopher consists perhaps in opening the mind of the scientist to this understanding; to make him hear that fundamental sound, or tone, of which I have spoken; and so to bring about a mediation between science and that wisdom which, notwithstanding its detractors, remains present and active, 1 am sure, in those lives which seem to us alien to the world of the mind only because we have the tiresome habit of judging them according to the singularly stunted modes of fashionable literature and philosophy. I am absolutely convinced that it is just this sort of screen that we must break through if we are to get closer to those secret regions where science and wisdom, without becoming identical, [altogether] converge. 